\title{
Intermetallic Evolution of Al-Si-Coated Hot Stamping Steel During Modified Electrically Assisted Rapid Heating
}

\author{
Kieu-Anh Dinh ${ }^{1} \cdot$ Sung-Tae Hong ${ }^{1} \cdot$ Tien Viet Luu ${ }^{1} \cdot$ Moon-Jo Kim² ${ }^{2}$ Heung Nam Han $^{3}$
}

Received: 3 January 2018/Revised: 14 February 2018/ Published online: 5 May 2018

(C) The Chinese Society for Metals and Springer-Verlag GmbH Germany, part of Springer Nature 2018

\begin{abstract}
Modified electrically assisted (EA) rapid heating of Al-Si-coated hot stamping steel is suggested, and the intermetallic evolution in the coating during heating is experimentally investigated. In the modified EA rapid heating, a continuous electric current for a suitable duration is applied to a specimen to heat it to a temperature slightly below the melting temperature of the coating. The temperature of the specimen is then kept constant for a specified dwell time. The result of the microstructural analysis shows that the modified EA rapid heating could effectively increase the thickness of the intermetallic layer between the coating and steel substrate much faster than conventional furnace heating and induction heating. The effectiveness of EA rapid heating may be due to the athermal effect of the electric current on the mobility of atoms, in addition to the well-known resistance heating effect. EA rapid heating also provides a technical advantage in that partial austenization can be easily achieved by properly placing the electrodes, as demonstrated in the present study.
\end{abstract}

Keywords Hot stamping $\cdot$ Electrically assisted rapid heating $\cdot$ Partial austenization $\cdot$ Al-Si-coated hot stamping steel

\section{Introduction}

In the automotive industry, due to the pressing demands of not only safety performance but also respect for the environment, the use of ultra-high-strength steel (UHSS) for lightweight automotive structures is a frequently considered strategy. UHSS is known to provide mechanical characteristics, including high-strength-to-density ratio and improved toughness, which satisfy the requirements of body-in-white component manufacturing such as B-pillar reinforcements, inner roof rails, and longitudinal rear rails.

However, applying UHSS to traditional sheet forming technologies induces various well-known technical difficulties. As the strength of the steel sheet increases, the

Available online at http://link.springer.com/journal/40195

Sung-Tae Hong

sthong@ulsan.ac.kr

1 School of Mechanical Engineering, University of Ulsan, Ulsan 44610, Republic of Korea

2 Liquid Processing \& Casting R\&D Group, Korea Institute of Industrial Technology, Incheon 31056, Republic of Korea

3 Department of Materials Science and Engineering, RIAM, Seoul National University, Seoul 08826, Republic of Korea essential forming load increases, and thus, the springback becomes larger [1-3]. The deformed parts can lack precision and contribute to structural defects such as cracks, wrinkles, and rough surfaces. Moreover, a high forming load during forming may cause deterioration of the forming equipment.

In order to overcome these drawbacks, hot stamping has been effectively used as a forming technology for UHSS. Hot stamping is a non-isothermal process carried out at high temperatures with the intention of eliminating springback [4]. Boron steel (typically 22MnB5) is commonly used as a material in the hot stamping process. Many researchers have carried out studies to investigate the thermomechanical flow properties of hot stamping steel during the hot stamping process. Merklein and co-researchers demonstrated that the forming ability of the hot stamping steel depends on the temperature, strain rate, and cooling rate $[5,6]$. In the hot stamping process, a boron steel sheet is heated slightly above the $\gamma \rightarrow \alpha$ transition temperature for a relevant dwell time to allow homogeneous austenization. Then, the heated sheet with a reduced flow stress (about $200 \mathrm{MPa}$ ) is deformed and subsequently die-quenched to achieve a tensile strength of about $1350 \mathrm{MPa}$ [7-9]. It is well known that the rapid cooling rate during die quenching creates a microstructure with a 
refined martensitic phase arrangement and uniformly distributed hardness without cracking [10].

The heating process is extremely important in hot stamping. Commonly employed methods are conventional heating using roller hearth furnaces [11] or induction heating using eddy currents $[12,13]$. Electrically assisted (EA) rapid heating (known as a smart hot stamping process), which was suggested by Mori et al. [14] can be an alternative heat treatment method in which the temperature is rapidly increased by resistance heating. This method can also induce partial heating in which a specific area of the specimen can be selectively heated. Therefore, EA rapid heating allows for forming inhomogeneous characteristic components such as the automotive B-pillar. For the automotive B-pillar, it is beneficial if the upper part has a martensitic structure to resist intrusion crashes, whereas the bottom part has a mixed bainitic and martensitic structure to absorb the crash impact.

In hot stamping, as a result of the elevated temperature, oxidation and decarburization on the surface of the heated steel sheet are generally inevitable. To prevent the aforementioned negative phenomena and to improve the corrosion resistance, a thin aluminized coating covering the surface of the boron steel substrate is frequently used [15]. There are two major types of hot-dip aluminized coatings currently used for hot stamping sheets. The first type consists of an $\mathrm{Al}-\mathrm{Si}$ alloy (7-11 wt\% $\mathrm{Si}$ ) which provides considerable coating resistance to oxidation and corrosion at elevated temperatures. The second type is pure aluminum with high reflection, which is mainly applied for reflective surface purposes [10]. Therefore, the first type (Al-Si coating) is extensively used to manufacture automotive hot stamping components and is the main subject of the present study.

During the hot stamping process, the transformation of the $\mathrm{Al}-\mathrm{Si}$ coating to an $\mathrm{Al}-\mathrm{Si}-\mathrm{Fe}$ intermetallic layer is imperative. The intermetallic layer, which is thermodynamically stable at temperatures higher than the melting temperature of the original $\mathrm{Al}-\mathrm{Si}$ alloy, will protect the steel substrate from inner penetrating oxidation and surmount the thermal expansion coefficient mismatch between the coating and steel substrate. In conventional methods, the intermetallic evolution could be naturally achieved via the slow heating rate. Borsetto et al. [16] showed that the steel diffusion process from the coating-substrate interface to the coating layer is thermally activated during hot stamping. Gui et al. [17] reported transformation of the Al$\mathrm{Si}$ coating into $\mathrm{Fe}-\mathrm{Al}$ intermetallic compounds after austenizing at $920{ }^{\circ} \mathrm{C}$ for $5 \mathrm{~min}$. It was also shown that the coating was composed of multiple intermetallic layers and a diffusion layer after heat treatment [18]. However, in the case of EA rapid heating, the development of intermetallic phases can be more difficult. Due to the rapid heating rate, the melting phenomenon dominates prior to a sufficient degree of intermetallic evolution in the Al-Si coating. In the present study, a solution to this technical difficulty is described (the modified EA rapid heating) and the corresponding intermetallic evolution of the $\mathrm{Al}-\mathrm{Si}$ coating during the heating process is experimentally investigated.

\section{Experimental}

Commercially available $22 \mathrm{MnB} 5$ boron steel sheets (thickness of $1.1 \mathrm{~mm}$ ) with hot-dipped coating layers (20 $\mu \mathrm{m} \mathrm{Al}-10 \mathrm{wt} \% \mathrm{Si}$ ) on the top and the bottom surfaces were used. The chemical composition of the primary steel substrate sheet is listed in Table 1. The presence of Mn and $\mathrm{B}$ elements in the chemical composition is beneficial to increase the hardenability and retard the heterogeneous nucleation of ferrite at the austenite grain boundaries. Specimens with a size of $250 \mathrm{~mm} \times 80 \mathrm{~mm}$ were prepared from the boron steel sheet along the rolling direction.

The modified EA rapid heating of the Al-Si-coated hot stamping steel specimen is schematically described in Fig. 1. First, the specimen is rapidly heated to a temperature slightly lower than the melting temperature of the $\mathrm{Al}-$ Si coating $\left(570{ }^{\circ} \mathrm{C}\right)$ by a continuous electric current. A pulsed electric current with a short duration is then applied to the specimen to keep the temperature isothermal for the specified dwell time. In the actual hot stamping process with modified EA rapid heating, the specimen would be heated by a continuous current again over the full austenization temperature after the isothermal dwell time, as described by the dashed line in Fig. 1. However, in the present study, the specimen was immediately water-quenched after the dwell time to observe the intermetallic evolution in the Al-Si coating during the dwell time by the pulsed electric current. The mechanical and microstructural properties of hot-stamped steels after full austenization followed by quenching have been discussed in many reports and will not be repeated here.

The experimental setup for the modified EA rapid heating consists of a power supply, two connecting cable wires, flat copper electrodes, and the test specimen, as schematically described in Fig. 2. A Vadal SP-1000U welder (Hyosung, South Korea) was used to generate a pulsed electric current and was operated using a programmable pulse controller. The copper electrodes were used to homogeneously distribute the electric current flowing through the specimen from the cathode to the anode. In order to avoid electric sparks at the electrodespecimen interface, the specimen was cleaned using ethanol prior to the experiment and tightly clamped using a press clamp. A set of bakelite insulators was used to 
Table 1 Chemical compositions of the hot stamping steel sheet (wt $\%)$

\begin{tabular}{lllllll}
\hline $\mathrm{C}$ & $\mathrm{Mn}$ & $\mathrm{Si}$ & $\mathrm{Al}$ & $\mathrm{Ti}$ & $\mathrm{B}$ & $\mathrm{Fe}$ \\
\hline $0.20-0.25$ & $1.10-1.30$ & $0.15-0.35$ & $0.02-0.06$ & $0.02-0.05$ & $0.002-0.004$ & Bal. \\
\hline
\end{tabular}

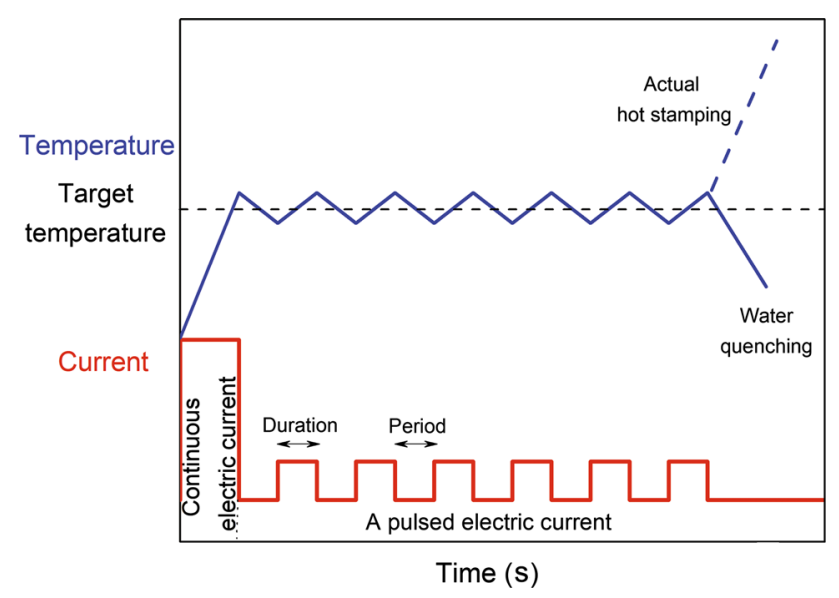

Fig. 1 A schematic of the procedure of modified electrically assisted rapid heating

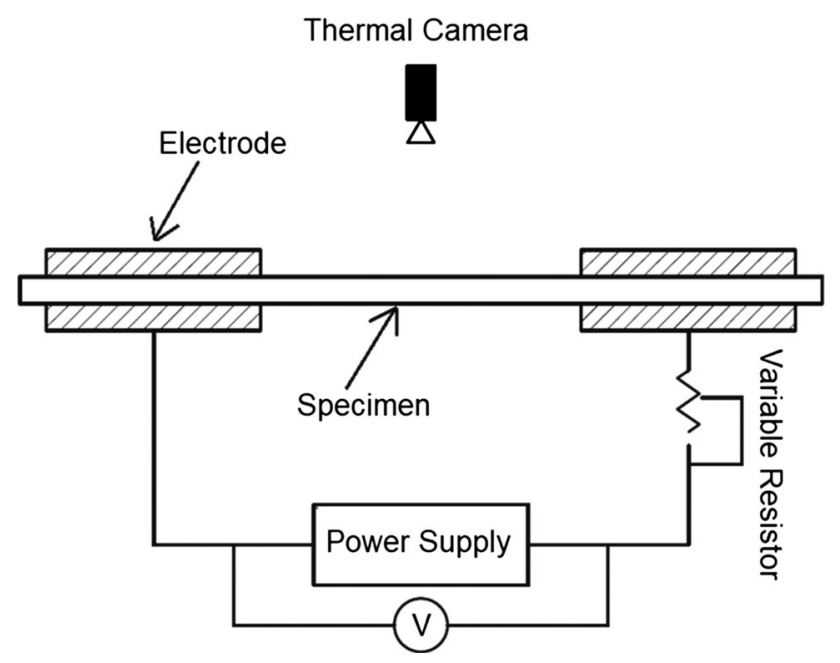

Fig. 2 A schematic of the experimental setup

insulate the experimental setup and guarantee the safety of the entire system.

In the modified EA rapid heating experiment, the specimen was heated using the electric current parameters listed in Table 2, which were selected as a result of separately conducted preliminary studies. Three different dwell times, 0,10 , and $25 \mathrm{~s}$, were considered in the modified EA rapid heating experiments. The temperature history along the surface of the specimen was monitored by an infrared thermal imaging camera (FLIR-T621, FLIR Systems, Oregon, USA) throughout the experiment. High-temperature black paint was applied to the surface of the specimen to stabilize the emissivity. The thermal imaging camera was then calibrated based on preliminary tests using a K-type thermocouple.

To evaluate the effect of electric current on the intermetallic evolution in the $\mathrm{Al}-\mathrm{Si}$ coating, comparative experiments were also carried out utilizing two conventional heating methods, furnace heating $(\mathrm{FH})$ and induction heating (IH). In furnace heating, the specimen was placed in a resistant furnace (Nabertherm Labotherm N7/H/B150, Nabertherm GmbH, Germany) to reach the target temperature of $570{ }^{\circ} \mathrm{C}$, and it was held at the target temperature for $25 \mathrm{~s}$ before water quenching. Note that the heating rate of the furnace heating was approximately $3{ }^{\circ} \mathrm{C} / \mathrm{s}$, which is significantly lower than that of modified EA rapid heating. Therefore, the specimen in the furnace heating was actually exposed to an elevated temperature for a significantly longer time than the specimen in the modified EA rapid heating. In the furnace heating test, a K-type thermocouple was physically attached to the surface of the specimen to monitor the temperature history. During induction heating, the temperature of the specimen was increased to the target temperature of $570{ }^{\circ} \mathrm{C}$ in $3 \mathrm{~s}$ and held constant over the $25 \mathrm{~s}$ dwell time. Once again, a K-type thermocouple was used to monitor the temperature history. It is well known that induction heating utilizes eddy currents, which is a skin (or surface) effect [19]. Therefore, the heating mechanism of induction heating is quite different than that of directly applying an electric current to the specimen. Thermal homogeneity during induction heating is mainly achieved by thermal conduction.

Microstructural analysis was performed via confocal laser scanning microscopy and a field emission gun scanning electron microscope (FE-SEM, Merlin compact, Carlzeiss, Germany) equipped with energy-dispersive $\mathrm{X}$-ray spectroscopy (EDS). Samples for the microstructural analysis were obtained from the tested specimens using a low-cycling diamond saw with dimensions of $1 \mathrm{~mm} \times 1$ $\mathrm{mm}$. Then, they were embedded in an electrically conductive polymer matrix. The cross sections of the samples were then prepared along the direction of the electric current by standard metallographic grinding and polishing finished with a $1-\mu \mathrm{m}$ diamond suspension followed by electropolishing using $10 \%$ perchloric acid. 
Table 2 Process parameter for modified electrically assisted rapid heating

\begin{tabular}{|c|c|c|c|c|c|c|}
\hline \multirow[t]{2}{*}{ Specimen } & \multicolumn{3}{|l|}{ Continuous electric current } & \multicolumn{3}{|c|}{ A pulsed electric current } \\
\hline & Electric current density ${ }^{\mathrm{a}}\left(\mathrm{A} / \mathrm{mm}^{2}\right)$ & Duration (s) & Electric current density ${ }^{\mathrm{a}}\left(\mathrm{A} / \mathrm{mm}^{2}\right)$ & Duration (s) & Period (s) & Number of pulses \\
\hline EA-0 & & & & & & 0 \\
\hline EA-10 & 57 & 3 & 14 & 2 & 2 & 3 \\
\hline EA-25 & & & & & & 6 \\
\hline
\end{tabular}

${ }^{a}$ Based on the original cross-sectional area of the specimen

\section{Results and Discussion}

In modified EA rapid heating, the average temperature of the heated region of the specimen reached the target temperature in $3 \mathrm{~s}$ (average heating rate of $190{ }^{\circ} \mathrm{C} / \mathrm{s}$ ) and was held nearly constant for the given dwell time, as shown in the temperature history of the EA-25 specimen (Fig. 3a). The temperature profile along the length of the EA-25 specimen at $1 \mathrm{~s}$ after the initiation of the dwell period also confirms that the temperature of the heated region was nearly uniform along the length at the target temperature (Fig. 3b). As marked in Fig. 3b, the temperature profile along the length of the specimen clearly shows three different temperature regions, a high-temperature (heated) region, transition region, and unheated region. At the edges of the electrodes, temperature transition regions exist and unheated regions are observed underneath the electrodes. The temperature history and profile in Fig. 3 confirm that the dwell at the target temperature could be easily achieved by applying a properly designed pulsed electric current.

The results of the SEM-EDS analysis on the cross section of the heated region show that the intermetallic evolution was significantly accelerated by the electric current. The thickness of the $\mathrm{Al}-\mathrm{Si}$ coating of the as-received specimen prior to the heating experiment was measured to be $18.48 \pm 1.6 \mu \mathrm{m}$. The cross section of the as-received specimen consists of three separate zones, as denoted in Fig. 4. Zone I describes the Al-Si coating, which has silicon aggregates embedded in the aluminum matrix. Note that the silicon element in the coating composition contributes to diminish the coating thickness and to flatten the interface between the coating and boron steel substrate during the hot-dip process [20-22]. Zone II is the thin $\mathrm{Fe}_{2} \mathrm{SiAl}_{7}$ intermetallic layer between the coating and steel substrate, which was induced from the prior hot-dip process. This zone is discontinuous along the length of the specimen with a maximum thickness close to $2.3 \mu \mathrm{m}$. Zone III is simply the boron steel substrate.

The cross-sectional microstructures of the coating after the heating experiments are shown in Fig. 5. Note that silicon has a similar atomic radius and molecular weight to aluminum. Therefore, it is assumed that silicon behaves similarly to aluminum in the coating for the microstructure analysis, and the coating is assumed to follow the binary $\mathrm{Al}-\mathrm{Fe}$ diagram in the present study [23]. At the dwell temperature $\left(570{ }^{\circ} \mathrm{C}\right)$, the intermetallic evolution in the
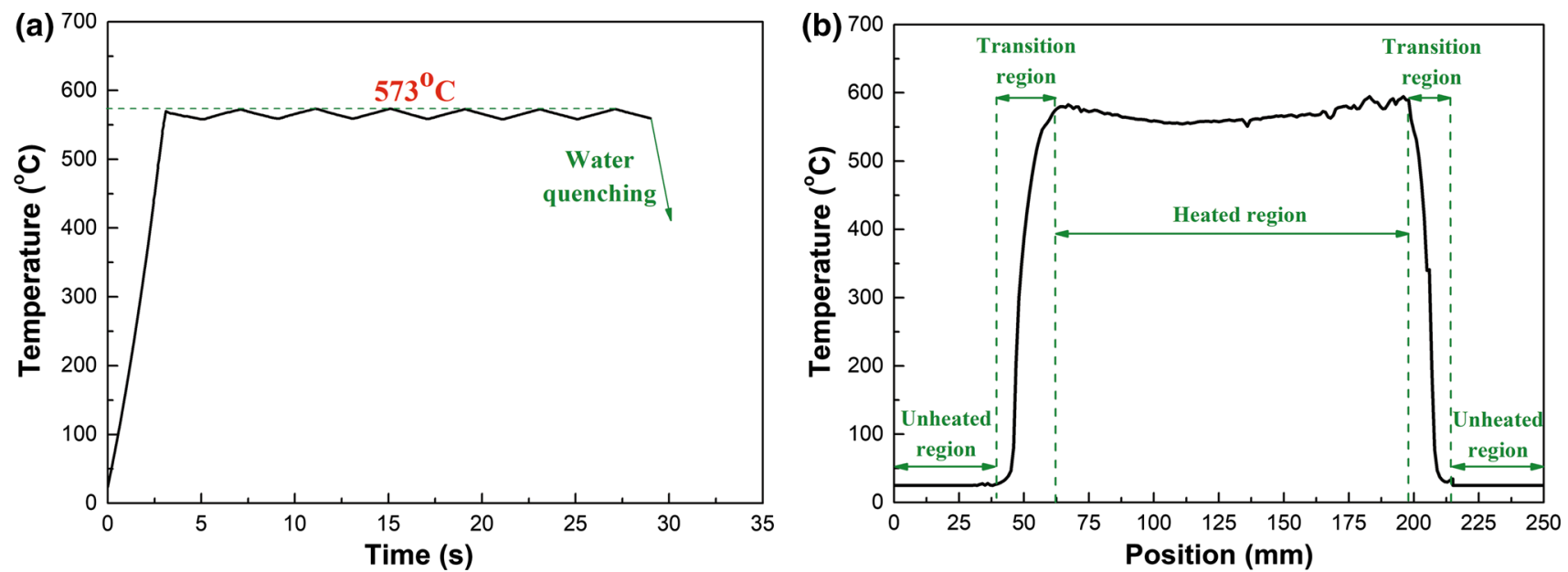

Fig. 3 a Temperature history of EA-25 specimen, $\mathbf{b}$ temperature profile along the length of the EA-25 specimen at $1 \mathrm{~s}$ after the initiation of the dwell period 


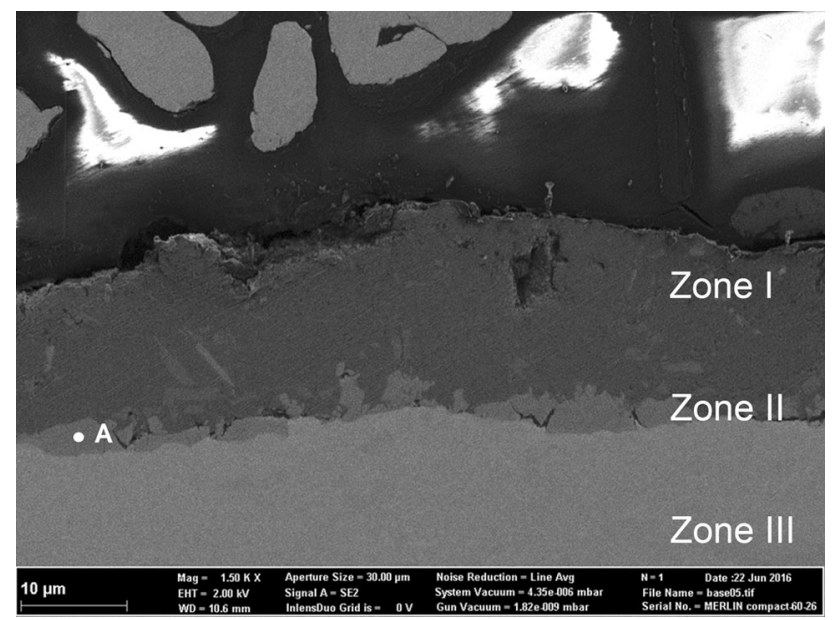

Fig. 4 Cross-sectional SEM-EDS micrograph of as-received specimen

coating depends on the diffusion between aluminum-silicon in the coating and boron steel substrate [24].

As indicated in Fig. 5 and summarized in Fig. 6, compared to the as-received specimen, the thickness of the intermetallic layer (zone II) of the heat-treated specimens increased for all three of the heating methods. It is very interesting to note that the diffusion process between the coating and boron steel substrate was significantly enhanced in the modified EA rapid heating process compared to furnace or induction heating. Even with a dwell time of $0 \mathrm{~s}$, the intermetallic layer of the specimen after the modified EA rapid heating $(5.04 \pm 0.66 \mu \mathrm{m})$ became thicker than the intermetallic layers of the specimens obtained after furnace heating $(3.75 \pm 0.13 \mu \mathrm{m})$ and induction heating $(3.24 \pm 0.58)$ with dwell times of $25 \mathrm{~s}$. Note that the results of furnace heating and induction heating are quite similar. In contrast to furnace and induction heating, the intermetallic evolution of the coating was nearly completed in the modified EA rapid heating process $(9.56 \pm 0.8 \mu \mathrm{m})$ with a dwell time of $25 \mathrm{~s}$. Note that a thin oxide layer $\left(\mathrm{Al}_{2} \mathrm{O}_{3}\right)$ was observed at the outer surface of coating for all the heat-treated specimens, probably due to heating in air and quenching in water.

The growth of the intermetallic phases is governed by chemical reactions at the interfaces and interdiffusion between different phases $[25,26]$. The phase constituents of the intermetallic layer (zone II) were quite different depending on the heating method and dwell time, as listed in Table 3. The phase constituents were determined by comparing the composition obtained from the SEM-EDS analysis to $\mathrm{Al}-\mathrm{Fe}$ equilibrium phase diagrams.

The coating of the EA- 0 specimen (dwell time of $0 \mathrm{~s}$ ) has an intermetallic layer composed of $\mathrm{Fe}_{4} \mathrm{Al}_{13}, \mathrm{FeAl}_{3}$, and $\mathrm{Fe}_{2} \mathrm{Al}_{5}$ intermetallics, while the $\mathrm{Fe}_{4} \mathrm{Al}_{13}$ intermetallic appears as a main component of the intermetallic layer. Note that a thin bright layer of $\mathrm{FeAl}_{3} / \mathrm{Fe}_{2} \mathrm{Al}_{5}$ was identified at the interface between the $\mathrm{Fe}_{4} \mathrm{Al}_{13}$ layer and steel substrate. For the EA-10 specimen (dwell time of $10 \mathrm{~s}$ ), the intermetallic phases are quite similar to those of the EA-0 specimen, except that the intermetallic layer became thicker. The circular islands in zone I of the EA-10 specimen were identified as the $\mathrm{FeAl}_{3}$ intermetallic. Note that these intermetallic compounds, which have a relatively
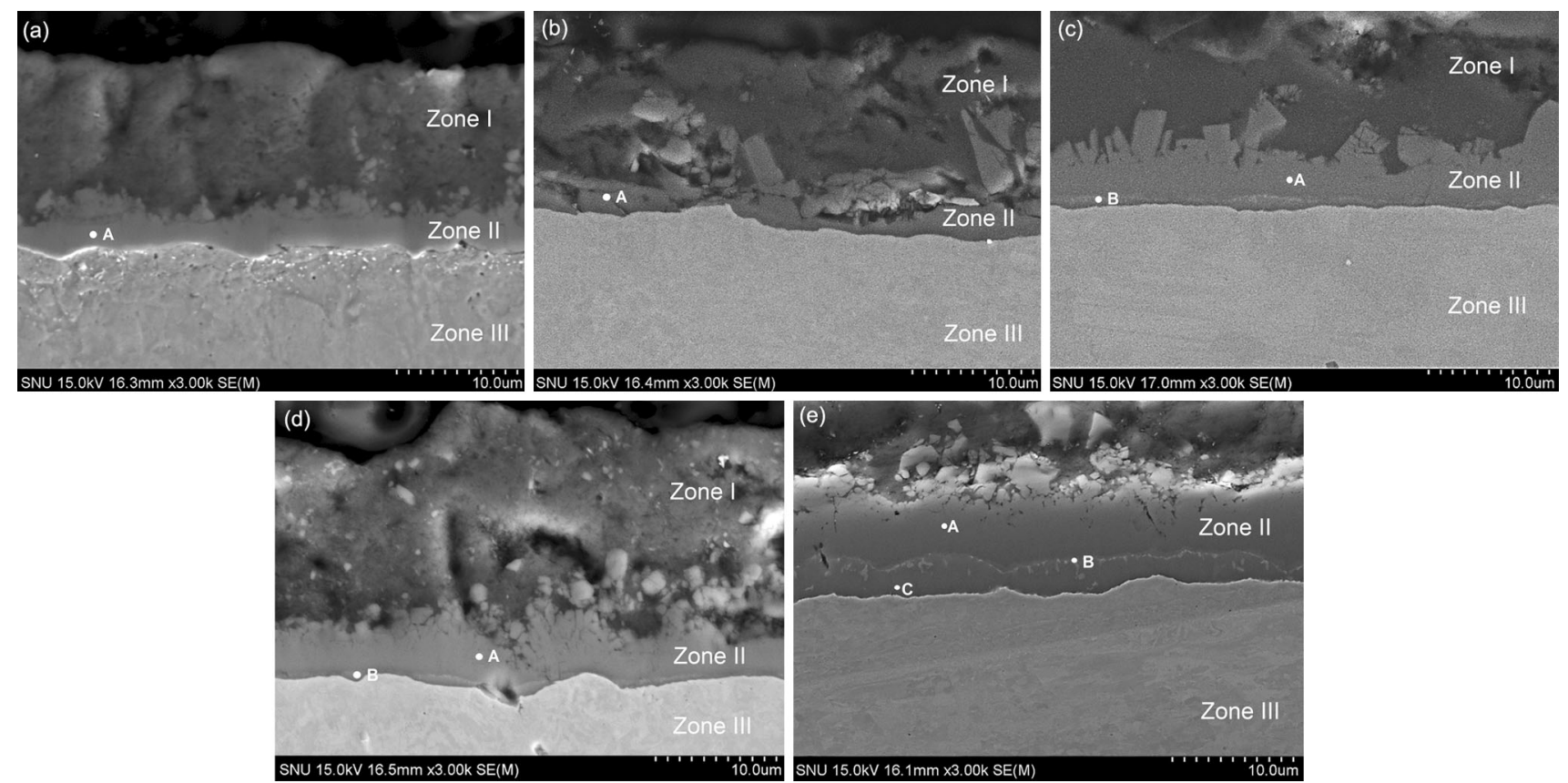

Fig. 5 Cross-sectional SEM-EDS micrograph of a CH specimen, b IH specimen, c EA-0 specimen, d EA-10 specimen, e EA-25 specimen 


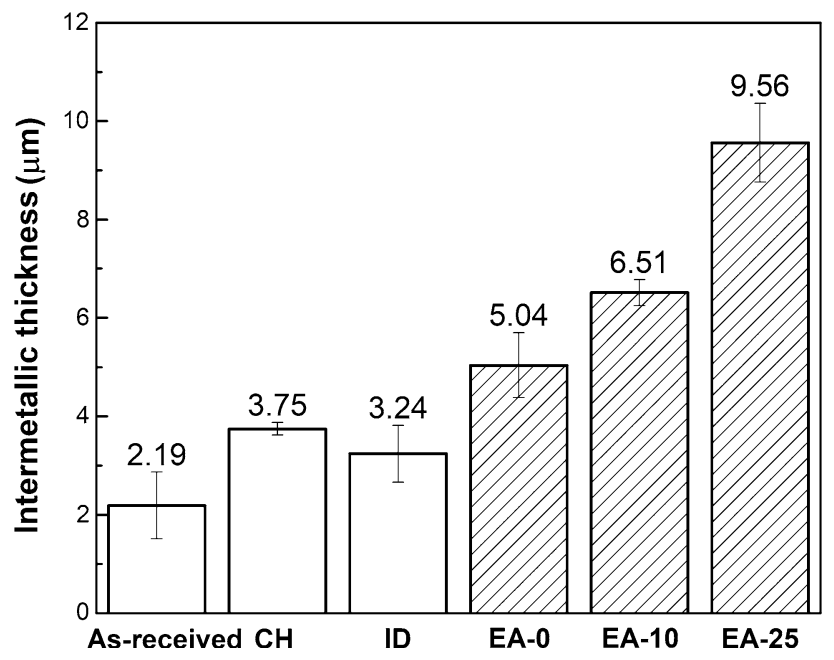

Fig. 6 Intermetallic thickness $(\mathrm{CH}$ furnace heating, $I D$ induction heating) higher aluminum content, are reported to have a quite low fracture toughness of $1 \mathrm{MPa} \mathrm{m}{ }^{1 / 2}$ and high hardness of 900-1150 HV0.05 [27]. Due to the inherent brittleness, these intermetallic compounds may promote the formation and propagation of cracks in the coating, which eventually cause damage of the steel substrate.

The coating of the EA-25 specimen (dwell time of $25 \mathrm{~s}$ ) exhibits complete intermetallic evolution, as mentioned above. A sandwiched FeAl intermetallic having a high iron content was observed between the aluminum-rich intermetallic $\mathrm{Fe}_{2} \mathrm{SiAl}_{7}$ and steel substrate, while a very thin layer of $\mathrm{FeAl}_{2}$ intermetallic was identified along the interface between the $\mathrm{FeAl}$ and $\mathrm{Fe}_{2} \mathrm{SiAl}_{7}$ intermetallics. The FeAl phase possesses a high fracture toughness of up to $26 \mathrm{MPa} \mathrm{m}^{1 / 2}$ and low hardness of 300-650 HV0.05 [28]. This intermetallic is reported to counteract crack formation in the coating [27].

Table 3 Phase constituents of intermetallic layer (zone II)*

\begin{tabular}{|c|c|c|c|c|c|c|}
\hline \multirow{2}{*}{ Specimen } & \multirow{2}{*}{ EDS point } & \multirow{2}{*}{$\begin{array}{l}\text { Thickness } \\
(\mu \mathrm{m})\end{array}$} & \multirow{2}{*}{ Phase constituents } & \multicolumn{3}{|c|}{$\begin{array}{l}\text { Chemical composition } \\
\text { (at.\%) }\end{array}$} \\
\hline & & & & $\mathrm{Fe}$ & $\mathrm{Si}$ & $\mathrm{Al}$ \\
\hline As-received & $\mathrm{A}$ & $2.19 \pm 0.68$ & $\mathrm{Fe}_{2} \mathrm{SiAl}_{7}$ & 19.42 & 12.82 & 67.75 \\
\hline $\mathrm{CH}$ & $\mathrm{A}$ & $3.75 \pm 0.13$ & $\mathrm{FeAl}_{3}$ & 21.01 & 12.42 & 66.58 \\
\hline ID & A & $3.24 \pm 0.58$ & $\mathrm{Al}$ rich & 12.51 & 17.40 & 70.09 \\
\hline \multirow{2}{*}{ EA-0 } & $\mathrm{A}$ & \multirow{2}{*}{$5.04 \pm 0.66$} & $\mathrm{Fe}_{4} \mathrm{Al}_{13}$ & 18.39 & 13.13 & 68.47 \\
\hline & $\mathrm{B}$ & & $\mathrm{FeAl}_{3}$ or $\mathrm{Fe}_{2} \mathrm{Al}_{5}$ & 23.39 & 9.85 & 66.75 \\
\hline \multirow{2}{*}{ EA-10 } & $\mathrm{A}$ & \multirow{2}{*}{$6.51 \pm 0.26$} & $\mathrm{Fe}_{4} \mathrm{Al}_{13}$ or $\mathrm{FeAl}_{3}$ & 18.39 & 13.13 & 68.47 \\
\hline & $\mathrm{B}$ & & $\mathrm{Fe}_{2} \mathrm{Al}_{5}$ & 23.39 & 9.85 & 66.75 \\
\hline \multirow{3}{*}{ EA-25 } & $\mathrm{A}$ & \multirow{3}{*}{$9.56 \pm 0.8$} & $\mathrm{Fe}_{2} \mathrm{SiAl}_{7}$ & 20.87 & 11.05 & 68.09 \\
\hline & $\mathrm{B}$ & & $\mathrm{FeAl}_{2}$ & 31.68 & 4.47 & 63.85 \\
\hline & $\mathrm{C}$ & & FeAl & 51.08 & 1.35 & 47.56 \\
\hline
\end{tabular}

*Zone I and zone III are always the Al-Si coating and the steel substrate, respectively; no zone I remains in case of EA-25 
This result suggests that the modified EA rapid heating effectively completed evolution of the intermetallic phases with a dwell time of $25 \mathrm{~s}$ and induced a beneficial intermetallic layer in the coating-substrate interface. The effectiveness of the modified EA rapid heating process may be due to the athermal effect of the electric current (in addition to the well-known resistance heating effect) on the mobility of atoms, as reported in the studies of the effect of electric current on the recrystallization kinetics [29] and the diffusion during electrically assisted brazing [30]. By further accelerating the mobility of atoms in the coating and steel substrate, modified EA rapid heating can expedite diffusion between the $\mathrm{Al}-\mathrm{Si}$ coating and boron steel substrate.

\section{Conclusion}

Modified electrically assisted (EA) rapid heating of Al-Sicoated hot stamping steel was suggested, and the intermetallic evolution in the coating during the heating process was experimentally investigated. As shown in the result of the microstructural analysis, the modified EA rapid heating effectively completed evolution of intermetallic phases with a dwell time of $25 \mathrm{~s}$ and induced a ductile intermetallic phase, which contributes to prevent crack formation in the coating. The completion of intermetallic evolution was clearly impossible for conventional furnace or induction heating with the same dwell time. The effectiveness of EA rapid heating may be due to the athermal effect of the electric current on the mobility of atoms, in addition to the well-known resistance heating effect. The modified EA rapid heating suggested in the present study provides a clear technical advantage over conventional heating methods. By effectively and significantly reducing the heating time necessary to stabilize the Al-Si coating, the cycle time of the hot stamping process can be significantly reduced. Also, the modified EA rapid heating process provides an additional technical advantage in that partial heating can be easily achieved by properly placing the electrodes as demonstrated in the present study.

Acknowledgements This work was supported by the National Research Foundation of Korea (NRF) grant funded by the Ministry of Science, ICT and Future Planning (MSIP) (NRF2015R1A5A1037627), and the Technology Innovation Program (Industrial Strategic Technology Development Program, 10044807. Development of technologies for vehicle body part made from UHSS and A15000 by electrically assisted manufacturing) funded by the Ministry of Trade, Industry and Energy (MOTIE, Korea).

\section{References}

[1] K. Mori, K. Akita, Y. Abe, Int. J. Mach. Tool. Manuf. 47, 321 (2007)

[2] K. Mori, Y. Okuda, CIRP Ann. Manuf. Technol. 59, 291 (2010)

[3] H. Kim, S. Han, Q. Yan, T. Altan, CIRP Ann. Manuf. Technol. 57, 299 (2008)

[4] M. Naderi, M. Ketabchi, M. Abbasi, W. Bleck, J. Mater. Process. Technol. 211, 117 (2011)

[5] M. Merklein, J. Lechler, M. Geiger, CIRP Ann. Manuf. Technol. 55, 229 (2006)

[6] M. Merklein, J. Lechler, J. Mater. Process. Technol. 177, 452 (2006)

[7] M. Geiger, M. Merklein, C. Hoff, Adv. Mater. Res. 6-8, 795 (2005)

[8] M. Thomas, R. Martin, K. Thomas, B. Gerald, K. Reiner, H. Dieter, S. Andreas, BHM 157(3), 97 (2012)

[9] D.W. Fan, B.C. Cooman, Steel Res. Int. 83, 412 (2012)

[10] K. Zhao, Y. Chang, P. Hu, Y. Wu, J. Mater. Process. Technol. 228, 68 (2016)

[11] M. Suehiro, K. Jusumi, T. Miyakoshi, J. Maki, M. Ohgami, Nippon Steel Technical Report No. 88 (2003), pp. 16-21

[12] R. Kolleck, R. Veit, M. Merklein, J. Lechler, M. Geiger, CIRP Ann. Manuf. Technol. 58, 275 (2009)

[13] H. Shen, Z.Q. Yao, Y.J. Shi, J. Hu, Acta Metall. Sin. (Engl. Lett.) 19, 190 (2006)

[14] K.I. Mori, T. Maeno, H. Yamada, H. Matsumoto, Int. J. Mach. Tool. Manuf. 89, 124 (2015)

[15] C. Allely, L. Dosdat, O. Clauzeau, K. Ogle, P. Volovitch, Surf. Coat. Technol. 238, 188 (2014)

[16] F. Borsetto, A. Ghiotti, S. Bruschi, Key Eng. Mater. 410-411, 289 (2009)

[17] Z.X. Gui, W.K. Lian, Y.S. Zhang, Mater. Des. 60, 26 (2014)

[18] K. Wang, Y. Jin, B. Zhu, Y. Zhang, Surf. Coat. Technol. 309, 282 (2017)

[19] J. Davies, P. Simpson, Induction Heating Handbook (McGrawHill, New York, 1979), pp. 308-310

[20] G. Eggeler, W. Auer, H. Kaesche, J. Mater. Sci. 21, 3348 (1986)

[21] W. Cheng, C. Wang, Intermetallics 19, 1455 (2011)

[22] W. Cheng, C. Wang, Surf. Coat. Technol. 205, 4726 (2011)

[23] D.W. Fan, B.C. Cooman, ISIJ Int. 50, 1713 (2010)

[24] H. Bakker, H.P. Bonzel, C.M. Bruff, M.A. Dayananda, W. Gust, J. Horvath, I. Kaur, G.V. Kidson, A.D. LeClaire, H. Mehrer, G.E. Murch, G. Neumann, N. Stolica, N.A. Stolwijk, H. Mehrer, Diffusion in Solid Metals and Alloys. (Springer, Berlin, Heidelberg, 1990)

[25] S. Kobayashi, T. Yakou, Mater. Sci. Eng. A 388, 44 (2002)

[26] A. Bouayad, Ch. Gerometta, A. Belkebir, A. Ambari, Mater. Sci. Eng. A 363, 53 (2003)

[27] M. Windmann, A. Rottger, W. Theisen, Surf. Coat. Technol. 226, 130 (2013)

[28] A. Kubosova, M. Karlik, P. Hausild, J. Prahl, Mater. Sci. Forum 567-568, 349 (2008)

[29] J.W. Park, H.J. Jeong, S.W. Jin, M.J. Kim, K. Lee, J.J. Kim, S.T. Hong, H.N. Han, Mater. Charact. 133, 77 (2017)

[30] V.T. Luu, T.K.A. Dinh, H. Das, J.R. Kim, S.T. Hong, H.M. Sung, H.N. Han, Int. J. Precis. Eng. Manuf. Green Technol. (2018) (in press) 